\title{
REVISITANDO A RECEPÇÃO DE FRANTZ FANON: O ATIVISMO NEGRO BRASILEIRO E OS DIÁLOGOS TRANSNACIONAIS EM TORNO DA NEGRITUDE ${ }^{1}$
}

\author{
Deivison Mendes Faustino \\ é Professor do Departamento de Saúde, Educação e Sociedade da Universidade Federal de \\ São Paulo.Santos, SP, Brasil.E-mail: deivison.faustino@unifesp.br \\ Orcid: 0000-0002-3454-7966 \\ http://dx.doi.org/10.1590/0102-303331/109
}

\section{Introdução}

Em que momento as ideias de Frantz Fanon chegaram ao Brasil e quais foram os seus principais interlocutores? Neste estudo, dialogo criticamente com a hipótese de um possível contato ou influência entre Fanon e alguns intelectuais ligados à Associação Cultural do Negro (ACN) no final da década de 1950 e início da década de 1960, para, em seguida, problematizar, de maneira mais ampla, o contexto de circulação das ideias fanonianas no Brasil.

Passados mais de 60 anos da publicação do seu primeiro livro, Peau noire, masques blancs (Fanon, 1952), pode-se observar na literatura internacional uma vasta produção teórica em torno do que seria o legado e a contribuição de Frantz Fanon para a compreensão da sociedade contemporânea. A lista honrosa de personagens por ele influenciados inclui nomes relacionados aos Black Panther Party, como Bobby Seale, Huey Newton e Angela Davis, nos Estados Unidos; Steve Biko, criador do Black Consciousness

1 Comunicação apresentada no Grupo de Trabalho de Cultura, Diferenças e Desigualdades do V Seminário Internacional do Programa de Pós-Graduação em Sociologia da UFSCar: Descentramentos, 2015. 
Movement, na África do Sul; Bobby Sands, membro influente do Irish Republican Army (IRA), na Irlanda do Norte; Ali Shariati, importante intelectual da revolução iraniana; o escritor e ativista paquistanês Tariq Ali; o filósofo argentino Enrique Dussel, formulador da filosofia da libertação; o brasileiro Paulo Freire, formulador da pedagogia da libertação; os críticos culturais anglófonos Edward Said, Homi Bhabha, Stuart Hall e Gayatri Chakravorty Spivak; o filósofo jamaicano Lewis Gordon; o filósofo e teórico crítico esloveno Slavoj Zizek; o geógrafo britânico David Harvey; a filósofa estadunidense Judith Butler, entre outros.

São intelectuais tão diversos em suas proposições e perspectivas quanto nos pressupostos teóricos e epistemológicos que sustentam suas posições. Por essa razão, vários estudiosos têm chamado a atenção para a existência de distintos "fanonismos", ou enfoques - mesmo que críticos - dados às reflexões elaboradas pelo autor (Faustino, 2015; Sekyi-Otu, 1996). Com vistas a essa diversidade, Lewis Gordon, Denean 304 Sharpley-Whiting e Renée White (1996) propõem uma sistematização temporal, dividindo-a em cinco grandes fases:

A primeira fase, de embocadura anticolonial e terceiro-mundista, vigorou do anos de 1950 até os anos de 1970, abrigando autores liberais, como Hannah Arendt e Sidney Hook; marxistas-leninistas como Nguyen Nghe e Jack Woddis, ou anticoloniais como Albert Memmi e Huey Newton. De acordo com os autores, essa fase, que mais se aproxima do período que discutiremos neste artigo, foi voltada às adesões ou rejeições imediatas - como é o caso de Arendt - à obra fanoniana, focando nos temas como violência e práxis revolucionária.

A segunda fase, por sua vez, vigente durante a década de 1970, é marcada pelas biografias produzidas por Peter Geismar, David Caute, Irene Gendzier, Patrick Ehlen, David Macey e, depois, pelo trabalho de Alice Cherki, caracterizados pelo interesse na trajetória pessoal de Fanon. Na terceira fase, iniciada na década de 1980, destacam-se os trabalhos de Hussain Adan, Emmanuel Hansen e Renate Zahar por evidenciarem 
a importância de Fanon para as ciências sociais e humanas; enquanto a quarta fase, iniciada ao final dos anos de 1980 e vigente ainda hoje, seria expressa pelo advento dos estudos culturais, pós-coloniais e pós-modernos na academia. Esse enquadramento, como argumentam os autores, teria sido inaugurado pelos trabalhos de Edward Said, Homi Bhabha, Abdul Jan Mohamed, Henry Louis Gates, entre outros.

Gordon, Sharpley-Whiting e White (1996) apresentam ainda uma quinta fase, a qual denominam "compromisso com o pensamento de Fanon para o desenvolvimento de seu trabalho". Esse período de estudos seria caracterizado pela busca de "elementos úteis em Fanon para entender a realidade atual" (Gordon, Sharpley-Whiting e White, 1996, p. 7). Para os autores, o livro Frantz Fanon and the psychology of oppression (Bulhan, 1985) é um texto inaugural dessa fase, que só se consolida em 1995 com a publicação de The hermeneutics of African philosophy, de Tsenay Serequeberhan (1994); Fanon's dialectics of experience, de Ato Sekyi-Otu (1996); e Fanon and the crisis of European man, de Lewis R. Gordon (1995).

Passados quase dez anos desde essa primeira sistematização, Lewis Gordon (2015) volta ao assunto em seu What Fanon said: a philosophical introduction to his life and thought, atualizando a lista de autores inseridos na quinta fase ao acrescentar nomes como Judith Butler, George Ciccariello-Maher, Drucilla Cornell, Nathalie Etoke, Nigel Gibson, Jane Anna Gordon, Neil Roberts, Henry Paget, Nelson MaldonadoTorres, Walter Mignolo, Boaventura de Sousa Santos, Michael Monahan, Alejandro J. de Oto, Richard Pithouse, Michel Contat, Michel Rybalka., Françoise Vergès, Sylvia Wynter, entre outros autores relacionados ao feminismo, à dependência global, à Africana theory, ao pensamento anticolonial, à filosofia latino-americana e à filosofia da libertação.

Gordon (2015) sugere ainda a emergência de uma sexta fase, considerada por ele como a emergência stricto sensu do Fanon studies. A esse período é atribuída a tarefa de caracterizar 
os estudos sobre Fanon a partir da prática teórica-político-filosófica da autorreflexão. É o momento em que o campo sabe e problematiza a própria existência. É importante lembrar aqui que Gordon é filósofo e, portanto, o emprego do termo "autorreflexão" não é fortuito, pois expressa a sua argumentação pela defesa de um campo teórico próprio. Essa fase, segundo ele, é inaugurada pela reflexão crítica de autores como Henry Louis Gates Jr., Anthony Alessandrini, Nigel Gibson e Cedric Robinson sobre o Fanons studies, e é ampliada pelos trabalhos de Jane Anna Gordon, Alejandro D. Oto, Michel Contat, Michel Rybalka, Mireille Fanon-Mendès-France, Sonia DayanHezbrun, Étienne Balibar, Achille Mbembe, Valentin-Yves Mudimbe, Matthieu Renault, Jean-Paul Rocchi.

A diversidade de abordagens a respeito da obra de Frantz Fanon também pode ser observada no Brasil, mas aqui uma série de fatores internos imprimirá uma lógica própria - embora não isolada do quadro acima descrito - na 306 recepção de Fanon. Como já foi abordado em outro lugar (Faustino, 2015), a recepção de Fanon no Brasil pode ser pensada em três grandes blocos temáticos e temporais: 1) a autenticidade nacional; 2) a autenticidade negra; e 3) o crescente interesse por Fanon.

O primeiro bloco, iniciado na década de 1960 e que vai até o final dos anos de 1970, foi protagonizado pela esquerda católica e/ou existencialista que se apoiará em Les damnés de la terre (1961), bem como na oposição inconciliável entre colonizadores e colonizados, para problematizar o imperialismo e a identidade nacional. O segundo bloco, também apoiado na polarização colonizador/colonizado, foi protagonizado pelos intelectuais do movimento negro, a partir da (re)ascensão do movimento no final década de 1970. O que diferencia os blocos - ambos apoiados em Les damnés de la terre-é que o primeiro pensará a colonização/descolonização em termos de classe, enquanto o segundo em termos de raça. O terceiro bloco, observado a partir dos anos 2000, é, por sua 
vez, marcado em primeiro lugar pela influência dos estudos culturais e/ou pós-coloniais britânicos no debate racial brasileiro - e pela sua adesão ao Peau noire, masques blancs (1952) ao invés de Les damnés de la terre (1961) - e, em segundo lugar, pela ampliação da participação negra nas universidades, fruto das ações afirmativas (Faustino, 2015).

O desafio assumido por este artigo é o de problematizar as pistas de uma recepção de Fanon no Brasil anterior a esses três blocos - a década de 1950 -, discutindo, portanto, de maneira mais ampla, as particularidades dessa recepção diante das características históricas, políticas e sociais em que a colonização, o racismo e a luta antirracista se erigiram no Brasil.

\section{A possível chegada de Fanon ao Brasil}

As perguntas a respeito de quando teriam se dado os primeiros contatos entre o pensamento de Fanon e os intelectuais brasileiros foram levantadas originalmente por trabalhos de pelo menos três importantes estudiosos da realidade brasileira: o livro Cultura brasileira e identidade nacional, de Renato Ortiz (2012); o artigo "A recepção de Fanon no Brasil e a identidade negra", de Antônio Sergio Guimarães (2008); e a seção "Frantz Fanon e o ativismo político-literário negro no Brasil: 19601980”, alocado no oitavo capítulo do livro A descoberta do insólito: literatura periférica no Brasil (1960-2000), de Mário Augusto Medeiros da Silva (2013a). No mesmo ano, esse autor publica um artigo intitulado "Frantz Fanon e o ativismo político-cultural negro no Brasil: 1960/1980" (Silva, 2013b), em que retoma o texto anterior de forma revisada. Esses estudos inauguraram a investigação sobre os possíveis caminhos pelos quais o pensamento de Fanon chegou ao Brasil.

Ao realizar uma busca exaustiva nos principais periódicos da década de 1950, procurando identificar quais teriam sido os possíveis ecos de Fanon entre a intelligentsia brasileira, Guimarães (2008, p. 100) afirma: "É como se a publicação de Peau noire, masques blancs (1952) tivesse passado despercebida”. 
$\mathrm{O}$ autor explica que, nessa época, a intelectualidade brasileira acompanhava atentamente tudo que se disponibilizava nos periódicos franceses em que Fanon publicou seus textos ou foi comentado. Como se sabe, em 1951 Fanon publicara "L'Expérience vécue du noir" na revista Esprit, n. 179, e em 1952 publica "Le syndrome nord- africain”, na edição n. 187. Em 1955, na edição n. 223 da mesma revista, lança "Antillais et Africains", enquanto em 1956 publica o seu magistral "Racisme et culture", na revista Présence Africaine. Em fevereiro de 1959 publica "Fondement réciproque de la culture nationale et des luttes de libération", ainda na revista Présence Africaine. Em 1959 e 1961, publica, respectivamente, "La minorité européenne d'Algérie en l'An V de la Révolution" e "De la violence", na famosa revista Les Temps Modernes.

Esses escritos não passaram despercebidos no debate francês, configurando-se como objeto privilegiado da análise para importantes autores que, por sua vez, foram lidos atentamente 308 pela intelectualidade brasileira da época. Curiosamente, insiste Guimarães (2008), nem a Revista Anhembi, coordenada por Roger Bastide e Florestan Fernandes no momento em que Bastide retorna de Paris, nem a revista Brasiliense, onde escreviam Clóvis Moura, Florestan Fernandes e Octavio Ianni, e nem mesmo as publicações de Sérgio Milliet sobre JeanPaul Sartre, Léopold Senghor, Aimé Césaire e outros temas referentes ao movimento de negritude renderam alguma referência direta ou indireta a Fanon, caracterizando, assim, um "silêncio impactante" (Guimarães, 2008, p. 99).

Duas décadas antes de Guimarães, Renato Ortiz (2012) já teria chegado a conclusões parecidas. Embora não fosse o seu objetivo mapear a recepção de Fanon, mas remontar as diferentes maneiras pelas quais a identidade nacional e a cultura foram discutidas nas ciências sociais brasileiras, Ortiz oferece importantes pistas para pensarmos essa recepção. Em primeiro lugar, como argumenta, há uma confluência entre os temas e os referenciais teóricos utilizados por Fanon e os intelectuais 
do Instituto Superior de Estudos Brasileiros (Iseb): da tradução francesa de Hegel por Hypolite e Kojeve dos anos de 1940, com o respectivo enfoque na "dialética do senhor e do escravo" como metáfora para a dominação social, econômica e cultural, à divulgação e circulação dos Manuscritos econômicos e filosóficos, de Karl Marx, em sua anunciada vinculação com Hegel; da ampla influência do humanismo de Jean-Paul Sartre $(1943,1956)$ às problematizações sobre a "situação colonial" de Balandier (1955), observam-se intrigantes similaridades nos usos dos conceitos fundamentais de alienação e situação colonial:

O célebre livro de Sartre L'Existentialisme est un humanisme é somente um dos escritos que enfatizam a dimensão humana da libertação, e mostra que o debate entre marxismo e existencialismo se realiza sob o signo do humanismo. $\mathrm{O}$ debate terá influências diretas em Fanon, que não hesitará em pensar a libertação nacional em termos de humanização universal do próprio homem. As repercussões são também nítidas nos pensadores do Iseb, e Álvaro Vieira Pinto não deixa de considerar o problema em seu livro Consciência e realidade nacional. (Ortiz, 2012, p. 51)

Ortiz sugere que as semelhanças entre Fanon e os pensadores do Iseb se expressavam, principalmente, através da "necessidade premente de uma busca por identidade", pois, segundo explica, "para além das categorias de colonizador/ colonizado, branco/negro, opressor/oprimido, permanece [em ambos] a pergunta 'quem somos nós?' ou 'por que estamos assim?" (Ortiz, 2012, p. 55). No entanto, apesar dessa notável confluência, o autor não observa nenhuma referência a Fanon nessa época de consolidação do Iseb:

Não estou insinuando que exista uma filiação direta entre o pensamento de Fanon e os intelectuais do Iseb, algo como uma influência de um sobre o outro. Tudo indica que os trabalhos de Fanon são elaborados sem maiores 
conexões com os pensadores nacionalistas brasileiros. Mas é justamente essa independência de pensamento que torna o problema mais interessante. A referência a um tipo de ideologia não brasileira introduz novos elementos para a compreensão do discurso isebiano e nos permite entender como a história penetra e estrutura o próprio discurso político. Por outro lado, ela dá uma abrangência maior à discussão da problemática do nacional, pois não se restringe à particularidade do quadro brasileiro. (Ortiz, 2012, p. 50)

Nem mesmo Guerreiro Ramos, que, ao que se sabe, bebeu em quase todas as fontes de Fanon, teria rompido o silêncio observado por Guimarães (2008). ${ }^{2}$ A possível explicação seria a diferença de horizontes entre os dois autores: enquanto Fanon buscava resolver os problemas coloniais através da práxis revolucionária no contexto da luta de classes, o sociólogo baiano, bem como o conjunto de pensadores do Iseb, tendia para posições nacionalistas e populistas (Guimarães, 2008; Ortiz, 2012). O fato é que, para Guimarães (2008), é apenas a partir da visita de Jean-Paul Sartre e Simone de Beauvoir ao Brasil em 1960 que o "silêncio sobre Fanon" se relativiza para dar lugar a uma "morna recepção" por parte da esquerda brasileira.

\section{Um novo personagem entra em cena}

Em um caminho diferente dos autores anteriores, Silva (2013a, 2013b) propõe analisar a recepção de Fanon no Brasil do período supracitado por um vetor até então pouco

\footnotetext{
2 A suposição segundo a qual Guerreiro Ramos conhecera (Guimarães, 2008) ou foi influênciado por Fanon (Filgueiras, 2012) ainda carece de investigação. $\mathrm{O}$ que se sabe é que ele não se refere ao autor martiniquenho em nenhum dos seus textos. Como afirma Guimarães (2008, p. 103), na 13 nota de rodapé de seu artigo: "Em A redução sociológica, de 1958, Guerreiro cita explicitamente Aimé Césaire (Discours sur le colonialisme, Paris: Présence Africaine,1955), Cheik Anta Diop (Nations nègres et culture. Paris: Présence Africaine, 1954) e Sartre ("Le colonialisme est un système". Les Temps Modernes, $\left.\mathrm{n}^{\circ} 126,1956\right)$ em francês, mas não se refere a Fanon. Na segunda edição, de 1965, Guerreiro acrescenta a essas leituras Balandier (Sociologie actuelle de l'Afrique noire. Dynamique des changements sociaux en Afrique centrale. Paris: PUF, 1955) e continua sem se referir a Fanon".
} 
explorado pela literatura que o antecedeu: o ativismo negro. Para tal, defendeu a existência de um fluxo de ideias esparso, mas importante, entre intelectuais africanos, afro-norte-americanos e afro-brasileiros entre o período de 1920 e 1960 que poderia oferecer algumas pistas relevantes ao debate:

A circulação de ideias sobre África ou de intelectuais e militantes africanos em São Paulo ainda carece de pesquisas mais articuladas. Memórias como as do militante José Correia Leite [...] ou entrevistas como a de Oswaldo de Camargo [...] mostram que, entre os anos 1920 e 1960, as associações negras paulistanas tiveram contatos esparsos com obras traduzidas, escritores, jornalistas e debates que remetiam a temas como o pan-africanismo, os movimentos que visavam ao retorno ao continente africano, as lutas anticoloniais e pela libertação de países, a violência do apartheid etc. (Silva, 2013b, p. 371)

A sugestão do autor é que a recepção de Fanon no Brasil poderia ser mais bem compreendida se focássemos nesse fluxo afro-transatlântico de ideias. Como se sabe, Frantz Fanon participou ativamente dos debates internacionais sobre a libertação dos países colonizados, circulando, portanto, entre os principais espaços de articulação política anticolonial (Faustino, 2018; Geismar, 1972; Gordon, 2015; Macey, 2000). A Associação Cultural do Negro, com sede em São Paulo, esteve presente em um desses espaços, a saber: o II Congresso de Escritores e Artistas Negros, ocorrido em Roma em $1959,{ }^{3}$ como se pode constatar menção à Geraldo Campos de Oliveira na lista de presença desse congresso:

\footnotetext{
${ }^{3}$ Como mostra Silva, ao retomar as memórias do militante José Correia Leite: "[Em 1959] O Geraldo Campos, ainda como presidente [da Associação Cultural do Negro], tinha ido ao II Congresso de Escritores e Artistas Negros realizado em Roma. [...] Em Roma já havia uma pessoa para representar o Brasil. Era o pintor Tibério, que morava em Paris. O Geraldo Campos trouxe de lá uma porção de documentos, teses e outras coisas, inclusive um distintivo que ele me deu, com o símbolo da revista Présence Africaine" (Leite e Cuti, 1992 apud Silva, 2013a, pp. 517-518).
} 


\section{Figura 1}

Lista de presença do II Congresso de Artistas e Escritores Negros, Roma, 1959 Destaque para Monsieur Campos de Oliveira, Brésil; Monsieur Frantz Fanon, Martinique; e Monsieur Tibério, Bresil
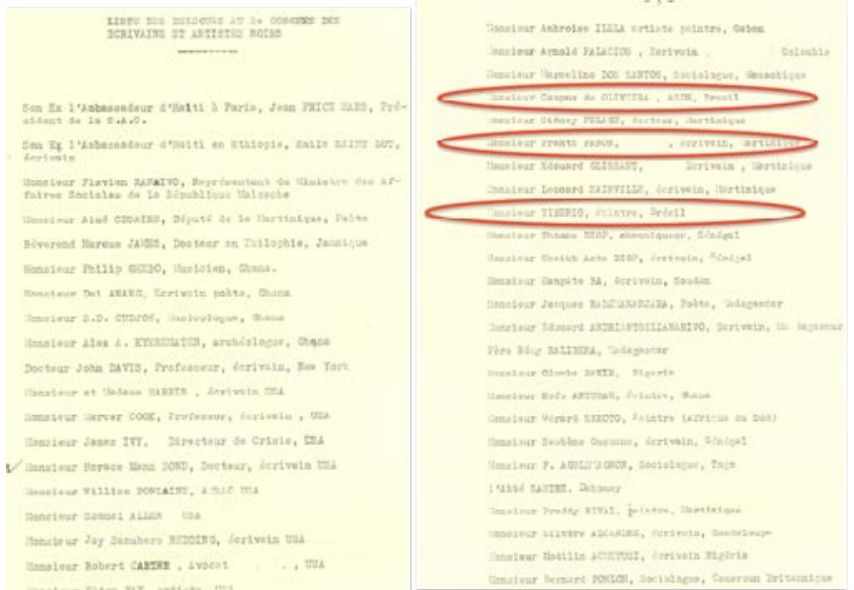

Fonte: Faustino (2015, p. 257).

Essa participação, segundo infere Silva (2013a), teria aberto a possibilidade de os intelectuais afro-brasileiros terem tido contato com as ideias e posições políticas de Fanon. Vale lembrar, a esse respeito, que embora a posição defendida por Fanon não tenha sido hegemônica (Marzioli, 2013) e ele próprio não tenha sido apresentado com o seu nome verdadeiro, ${ }^{4} \mathrm{o}$ autor e ativista estava entre as figuras mais notáveis do Congresso (Cannelli, 2007). Entretanto, como reconhece Silva (2013a), essa hipótese de um possível encontro ainda carece de fontes mais específicas para ser confirmada:

${ }^{4}$ Como relatou Amady Aly Dieng na ocasição de comemoração do $50^{\circ}$ aniversário da Présence Africaine: "Neste memorável congresso houve vários incidentes. O governo francês era hostil à presença do dr. Frantz Fanon, membro da FLN Frente de Libertação Nacional, que foi obrigado a se pronunciar sob o pseudônimo de Dr. Oumar" (Dieng, 2006, p. 109). 
Dadas as informações lacunares, é difícil afirmar, sem pesquisa exaustiva no acervo da associação, o que Oliveira um dos representantes brasileiros - efetivamente carregou consigo de Roma, qual nível de discussão foi capaz de estabelecer no congresso, seu domínio de línguas estrangeiras [em particular, o francês] e, o mais importante para agora, se conheceu Fanon e se interessou pelo mesmo. (Silva, 2013a, p. 518)

Ainda assim, a despeito da carência de fontes, as pistas levantadas oferecem um animador convite à reflexão, especialmente quando observadas à luz das apropriações que os intelectuais afro-brasileiros das décadas seguintes estabeleceram com o pensamento de Fanon. O ativismo cultural negro da década de 1980, por exemplo, elegerá justamente os textos fanonianos - apresentados por Fanon no I e II Congresso de Escritores e Artistas Negros, em 1956 e 1959, respectivamente - como referência para pensar as relações entre cultura negra, colonização e luta política. ${ }^{5}$

Silva (2013a) observa uma importante troca de ideias entre a ACN, a Présence Africaine e alguns outros intelectuais do movimento de negritude nos anos de 1950 e no início da década de 1960. Essa troca apontaria, já em 1959, para uma relação muito mais próxima do que se imaginava. Como comprova a carta encontrada pelo autor na Coleção da Associação Cultural do Negro, no Acervo Ueim-UFSCar, escrita pelo vice-presidente da ACN aos jornais da época:

\footnotetext{
5 Ao analisar a produção intelectual de Márcio Barbosa no Quilombhoje, Silva (2013a, p. 519) conclui: "Suas fontes bibliográficas citam, entre outros: Os condenados da terra (1979), com o texto 'Sobre a cultura nacional'; e 'Racismo e cultura', publicado em tradução portuguesa no livro Em defesa da revolução africana, em 1980". Antes, este livro é o original Pour la révolution africaine, conjunto de ensaios dispersos editado pela François Maspero em 1969 e traduzido em Portugual pela Sá da Costa Editora, na "Coleção Terceiro Mundo". "Racismo e cultura" é a conferência de Fanon ao I Congresso de Escritores e Artistas Negros (1959); "Sobre a cultura nacional" é a sua conferência de 1959, para a segunda edição do evento.
} 
A "Société Africaine de Culture", ciente da importância da contribuição dada pelo elemento africano à cultura do Brasil, acolheria com imensa satisfação uma representação de nosso país. Por isto, solicitou à Associação Cultural do Negro [...] para que [se] tornasse intérprete de tal desejo, pedindo outrossim divulgar as notícias referentes ao conclave e possivelmente tomar contato com o ambiente cultural do país, assinalando as figuras que dele desejam participar. Solicitamos então aos intelectuais negros e aos estudiosos eventualmente interessados no assunto, o envio de sua adesão, para que a ACN possa transmiti-la à "Société Africaine de Culture", recolhendo, outrossim, os pormenores sobre a viagem para conhecimento daqueles que desejam participar do Congresso. [...] A "S.A.C", com a qual a Associação Cultural do Negro deseja estabelecer laços de amizade e de profícua colaboração, sugeriu também a criação no Brasil de uma associação “Amis de Présence Africaine”, com membros brancos e negros, objetivando estudar os problemas ligados à cultura afro-brasileira e a divulgação de todas as manifestações relativas a ela [...] A Associação Cultural do Negro aproveita então esta oportunidade para lançar o seu apelo aos intelectuais brasileiros, negros e brancos, para que seja fundado em São Paulo um centro filiado à "S.A.C" digno de representar no estrangeiro a cultura africana no Brasil. Com este objetivo a A.C.N fará realizar dia 27 de fevereiro próximo, em sua sede social, uma reunião para tratar do assunto, estando desde já convidados todos os interessados [...] Finalmente, o senhor Alioune Diop, Secretário Geral da "Société Africaine de Culture", solicita o apoio e a solidariedade da intelectualidade brasileira, das associações culturais e das entidades que congregam o elemento negro, traduzidos no envio de mensagens por ocasião do congresso. (Américo Orlando da Costa, 1959 apud Silva, 2012, pp. 250-251) 
Em outro trecho, Silva (2012) relata, a partir dos dados encontrados, que o contato afro-atlântico-diaspórico da ACN não se resumiu à sua participação no Congresso de Roma, em 1959, pois seguiu ativo e possibilitando frutos diversos, dos quais o mais notável é a participação de alguns de seus membros em uma edição organizada por Léon Damas, importante articulador internacional do movimento de negritude:

\begin{abstract}
Todavia, não foi apenas a eles que a ACN despertava curiosidade. Léon Gontran Damas, para organizar com poetas brasileiros a sua Nouvelle somme de poésie du monde noir, editada em francês, inglês, português e espanhol pela Présence Africaine [...], recorre àquele conglomerado de ativistas. Ali, segundo Camargo, toma conhecimento e recolhe os poemas de Natanel Dantas, Eduardo de Oliveira, Carlos de Assumpção, Luiz Paiva de Castro, Marta Botelho e do próprio entrevistado. Quase uma década antes, o poeta cubano Nicolas Guillén, a quem Solano Trindade dedicou um poema em Cantares ao meu povo, também já havia travado contato com alguns dos frequentadores da agora ACN - em particular Correia Leite. (Silva, 2012, p. 247)
\end{abstract}

Embora essa rede (afro) transnacional de influências recíprocas anteceda o período aqui analisado, ${ }^{6}$ ela adquire uma dimensão mais ampla sob a economia moral do antifascismo

${ }^{6}$ Clóvis Moura (2013), em seu Dicionário da escravidão negra no Brasil, dedica um capítulo inteiro à revolução haitiana e a sua influência nas lutas negras de todo o continente americano, inclusive em ações políticas antiescravistas como a Inconfidência Baiana, de 1978, a Pedrosada, de 1823, a Revolução de 1817, em Pernambuco, entre outras. Em outro lugar, ao elencar os diversos peródicos publicados pela imprensa negra brasileira das primeiras décadas do século XX, destaca um veículo que expressa bem o quanto o associativismo negro estava atento aos acontecimentos internacionais. Segundo ele: "O [periódico] Menelik foi um dos primeiros jornais associativos que surgiram em São Paulo, criado pelo poeta negro Deocleciano Nascimento [...]. Esse Menelike, por causa da época da guerra da Abissínia com a Itália, teve repercussão muito grande dentro de São Paulo. Todo negro fazia questão de ler o Menelik" (Moura, 1983, pp. 53-54). 
de meados do século XX. Temas como "alienação”, "emancipação" e "libertação nacional" passam a circular entre importantes intelectuais do então chamado "terceiro mundo" (Ortiz, 2012), especialmente aqueles posicionados a partir das diversas localidades da diáspora africana, que se apropriarão dos termos em voga para decodificarem as diversas facetas da política racializada (Gilroy, 1992). Nesse cenário, é plausível supor que os intelectuais afro-brasileiros presentes no já mencionado congresso pudessem ter tido contato e, eventualmente, se interessado pelas ideias de Fanon.

Entretanto, se considerarmos seriamente essa hipótese restará ainda um elemento a ser encarado - uma vez que a pouca disponibilidade de fontes nos limita quanto a fazer suposições ${ }^{7}-$, que é a relação entre sincronicidade e diacronicidade, não apenas da racialização, mas sobretudo das agências atlânticas negras que se estabeleceram nas diferentes partes da diáspora africana (Gilroy, 1992, 2000). Para além do já comprovado fluxo 316 de influências políticas e estéticas afro-diaspóricos, resta ainda se questionar em que medida as perguntas e problemas enfrentados pelos já mencionados intelectuais afro-brasileiros poderiam encontrar guarida nas respostas oferecidas por Fanon no Congresso de Roma. Como veremos, é exatamente nesse aspecto que as informações parecem não se encaixar.

\section{Fanon seria útil ao antirracismo brasileiro dos anos de 1950 ?}

O confronto entre as perspectivas defendidas pelos intelectuais da Associação Cultural do Negro (ACN) à época do II Congresso de Artistas e Escritores Negros, em Roma, em 1959, e as posições defendidas por Fanon nesse mesmo período sugerem algumas diferenças substanciais entre eles, especialmente nos temas referentes à relação entre cultura

\footnotetext{
7 Silva $(2012,2013 a, 2013 b)$ chama a atenção para a necessidade de pesquisas mais exaustivas na Coleção Associação Cultural do Negro, no Acervo Ueim-UFSCar.
} 
(estética) e política. Essa diferença, como procuraremos argumentar, dificultaria a absorção das ideias de Fanon por parte dos intelectuais brasileiros do período.

Para Fanon, por exemplo, seria a ruptura radical por meio de uma práxis revolucionária anticolonial - e não a integração ou a afirmação da cultura - os elementos que poderiam levar o colonialismo a termo. No contexto do Congresso, a atuação de Fanon como embaixador e mobilizador político e revolucionário da Frente de Libertação Nacional da Argélia junto aos países da África subsaariana, o avançar das lutas de libertação, resultando nas independências de países como Sudão, Marrocos e Tunísia (1956), Gana (1957), Guiné (1958) e o advento da revolução cubana poucos meses antes do II Congresso influenciaram decisivamente a forma de Fanon pensar a relação entre cultura e política, levando-o a se diferenciar ainda mais das posições defendidas pela maioria dos intelectuais do movimento de negritude à frente da revista Présence Africaine, ${ }^{8}$ com o qual os brasileiros tinham bastante proximidade.

Em sua conferência no II Congresso, Fanon afirma que a "condição de existência da cultura é, pois, a libertação nacional, o renascimento do Estado" (Fanon, 2010, p. 280). Isso significa que, para ele, o caminho que deveria ser adotado pelos intelectuais presentes não deveria ser o enaltecimento da cultura africana - sistematicamente negada pelo jugo colonial -, mas o engajamento dos artistas, junto ao povo colonizado, seus saberes e (pré)conceitos, em direção a uma práxis política de transformação das condições concretas de existência. Seria apenas a partir desse engajamento rumo à construção da nação, encarnando "as aspirações reais do povo" e, principalmente,

\footnotetext{
8 Vale lembrar, como já discutimos em outro espaço (Faustino, 2013), que algumas dessas diferenças já se observam em Peau noire, masques blancs (1952) e "Racisme et culture" (1945), quando Fanon denuncia um certo essencialismo e culturalismo nas posições defendidas pelo movimento de negritude.
} 
modificando o Estado, que seria possível, segundo o autor, o surgimento de "formas de fecundidade cultural excepcional” (Fanon, 2010, p. 281), como se pode ler no mesmo trecho, apresentado no Congresso:

Pensamos que a luta organizada e consciente empreendida por um povo colonizado para restabelecer a soberania da nação constitui a manifestação mais plenamente cultural que exista. Não é unicamente o sucesso da luta que dá, posteriormente, validade e vigor à cultura, não há hibernação da cultura durante o combate. A própria luta, no seu desenrolar, no seu processo interno, desenvolve as diferentes direções da cultura e esboça novas orientações. A luta de libertação não restitui à cultura nacional o seu valor e os seus contornos antigos. Essa luta, que visa uma distribuição fundamental das relações entre os homens, não pode deixar intactos nem as formas nem os conteúdos culturais desse povo. (Fanon, 2010, pp. 280-281)

Fora desse movimento prático-sensível, restariam, para ele, apenas duas opções: adorar a cultura do colonizador, legitimando-a enganosamente como a única verdadeiramente válida e contribuindo, assim, para disseminar preconceitos em relação à cultura autóctone, ou lançar-se apaixonadamente à cultura dos povos colonizados, cultura esta "mumificada", "substancializada", "solidificada" e "esterilizada" pelo colonialismo. Essa segunda opção que, para Fanon, é partilhada pela maioria dos intelectuais do movimento de negritude - foi alvo de duras críticas ao longo deste e de outros textos escritos pelo autor. Não é à toa que a coletânea de textos apresentados à Conferência dos Intelectuais da África e da Diáspora, organizada em 2004 pela União Africana, em Dakar, apresenta alguns trechos do capítulo IV, "Sur la culture nationale", 
de Les damnés de la terre (1961), sob o título "A crítica da negritude por Frantz Fanon". ${ }^{9}$

O discurso de Alione Diop para a primeira edição da revista Présence Africaine, em 1947, explicita bem as diferenças que futuramente Fanon assumiria, pois segundo Diop a revista estaria aberta à colaboração daqueles que estivessem dispostos a ajudar a "definir a originalidade africana e acelerar a sua inserção no mundo moderno" (Diop, 2006, p. 100), já que a Europa, "uma minoria de seres que produzem e criam", impôs ao resto do mundo, os "menos ativos", que "produzem menos", a sua "produtividade" (Diop, 2006, p. 101). A esse modo "patológico" e "militante" da Europa, deve se opor, portanto, a "sensibilidade muito viva e uma história longa e singular” (Diop, 2006, pp. 102-103), própria de uma humanidade negra:

A língua pela qual essa humanidade vai se exprimir em nossa revista (o francês) não deixará de revelar novas temáticas pitorescas e morais e formais inéditas de sensibilidade. Acrescentaríamos até que esta humanidade negra pode enriquecer a civilização europeia. Estamos convencidos de que sim. Pois um dos traços característicos da vida moderna é acreditar que as consciências podem se comunicar entre si. O negro-africano, por sua vez, não acredita nisso. Para ele, de fato, não falta prazer no amor e na amizade, mas ele desconhece um pouco a intimidade. Pelo contrário, os europeus acham até que o ser humano só é real quando pode expressar a sua humanidade. As instituições sociais o consideram dentro deste quadro somente. [...] Todo o ser humano que não manifestar sua personalidade é negado nesta sociedade militante, na qual cada um assume

\footnotetext{
9 A coletânia disponibiliza o texto de resolução dos congressos pan-africanistas e algumas das conferências que permearam as suas reflexões (Fanon, 2006). O trecho pode ser encontrado nas páginas 177-186 da edição brasileira de 1979 (Ed. Civilização Brasileira) e nas páginas 246-259 da edição de 2010 (Ed. UFJF).
} 
inteiramente o seu próprio destino, na qual só se valorizam as leis e os fatos, revelados pela ciência e pelo pensamento [...]. Quanto a nós, africanos, esperamos destas atividades culturais resultados bem específicos. Que Présence Africaine nos franqueie uma inserção e um posicionamento na sociedade moderna, ao mesmo tempo que nos revele ao mundo, nos ensinando a crer na ideia. Pois ainda somos bem diferentes do europeu em relação a isso [...]. O universo é, para nós, ilimitado em maravilhas, é fecundidade infinita oferecida ao nosso vigoroso apetite. Nos preocupamos pouco em conhecer e domar o mundo, mas sim em usufruir dos alimentos que a atualidade presente carrega. Vivemos hic et nunc. De certa maneira, somos burgueses lá onde o europeu é um militante. (Diop, 2006, p. 103)

É óbvio que essa visão essencialista foi ressignificada ao longo dos anos com o desdobramento das lutas de libertação nos diversos países africanos e que a revista Présence Africaine não ficou imune às novas influências, mas até o período do II Congresso as ideias hegemônicas estavam entre o movimento de negritude cultural, de Léon Damas, Aimé Césaire, Léopold Senghor e Alione Diop, e o faraonismo, de Cheikh Anta Diop. O primeiro buscava "reabilitar" a raça negra a partir da estética, em especial a ideologia e a poesia, enquanto o segundo almejava ser uma forma "científica de negritude", voltada à exaltação de um passado negro glorioso. ${ }^{10} \mathrm{O}$ ponto é que a posição radical de Fanon era sabidamente crítica dessas duas tendências e poderia ter ganhado um eco maior nos anos de independência que se

${ }_{10}$ Dieng (2006, p. 112) lembra que, a despeito dessas duas vertentes dominantes, a "Présence Africaine não deixa de publicar obras de tom anticolonialista, como $O$ discurso sobre o colonialismo, de Aimé Césaire; Os estudantes negros falam (1953), As massas africanas e a atual condição humana (1956) e A companhia do Senegal (1958), de Abdoulaye Ly; Carta a Maurice Thorez (1956), de Aimé Césaire; A contribuição ao estudo dos problemas políticos na África negra (1958), de Mahjemout Diop; A África negra pré-colonial e A unidade cultural da África negra (1960), de Cheikh Anta Diop”. 
seguiram, se não fosse a sua morte precoce aos 36 anos, em 1961. Enquanto isso, no II Congresso, ele defendia uma abordagem da cultura que pudesse ser articulada a partir da luta (revolucionária) pela construção da nação, pelos desejos e visões de mundo do povo e por uma visão humanista e internacionalista que refutasse o nacionalismo, o particularismo e qualquer visão reificada de identidade:

Se o homem é o que ele faz, então diremos que a coisa mais urgente hoje para o intelectual africano é a construção da sua nação. Se essa construção for verdadeira, isto é, se traduzir a vontade manifesta do povo, se revelar em sua impaciência os povos africanos, então a construção nacional se acompanhará necessariamente da descoberta e da promoção de valores universalizantes. Longe, pois, de afastar-se das outras nações, é a libertação nacional que torna a nação presente no palco da história. É no coração da consciência nacional que se eleva e se vivifica a consciência internacional. E essa dupla emergência é apenas, definitivamente, o núcleo de toda cultura. (Fanon, 2010, p. 283)

Já o ativismo brasileiro daquele momento, revela Silva (2012), buscava respostas bastante distintas para as suas questões políticas e estéticas. Como se pode constatar no manifesto escrito pelos intelectuais da $\mathrm{ACN}$, na ocasião de comemoração dos 70 anos da abolição da escravidão, havia pouco ou nenhum espaço para o radicalismo defendido por Fanon:

Neste ano de 1958, em que comemoramos o $70^{\circ}$ aniversário da abolição da escravatura no Brasil, as organizações culturais, esportivas, recreativas e as pessoas que a este subscrevem, uniram-se para homenagear os grandes vultos que, no passado, batalharam nas tribunas, na imprensa, nos parlamentos, nos eitos, nas senzalas e nos quilombos por causa tão justa e humana. [...] Tais vultos 
merecem a homenagem e o respeito de todo o povo brasileiro, e, os ideais de liberdade e independência que nortearam suas grandes ações, elevam e enobrecem os sentimentos de humanidade de nossa gente. [...] No momento em que se exaltam no Brasil os sentimentos de nacionalidade, independência e liberdade, adquire ainda maior oportunidade a comemoração do grande feito de 1888 [...] Através de sessões cívicas, conferências culturais, representações de teatro, festejos populares, atividades esportivas e recreativas, desejamos que todos os brasileiros participem das festividades comemorativas do "O Ano 70 da Abolição”, contribuindo dessa maneira para elevar ainda mais alto a chama democrática da igualdade jurídica e social das raças. Salve o Ano 70 da Abolição. [São Paulo, janeiro de 1958]. (Carta da ACN apud Silva, 2012, p. 243)

O tom agregador da carta, explica Silva, corresponde 322 à necessidade de congregar os elementos mais díspares da sociedade em um acontecimento considerado de maior importância e é reveladora quando contrastada com o discurso de Fanon, acima apresentado. Para além disso, o fantasma da repressão política sofrida pela Frente Negra Brasileira, associada às características próprias do racismo brasileiro, ${ }^{11}$ fazia com que, nesse momento, os mentores de diversas organizações negras apostassem mais nas formas culturais de articulação política do que nas formas clássicas de enfrentamento. Como afirma o autor a respeito da ACN:

Criada como um fato político e cultural, por mais que seus mentores quisessem minimizar o primeiro adjetivo, ela se torna uma referência do ativismo negro, sendo chamada a emitir

\footnotetext{
11 Hanchard (2001), olhando um momento distinto deste que ora analisamos, sugere em seus estudos que a aglutinação de negros em torno das entidades de cunho cultural - em detrimento das organizações políticas - foi uma estratégia bastante utilizada no Brasil, dada a perseguição sistemática à auto-orgnização negra.
} 
opinião ou se posicionar sobre os mais diversos assuntos, em diferentes momentos, acerca de questões que nem sempre pôde dar a resposta esperada. (Silva, 2012, p. 247)

Assim, embora o ano de 1959 seja um momento decisivo para as lutas de libertação que se seguiram no continente africano, cujos desfechos bem ou malsucedidos não passaram batido a esses intelectuais e ativistas afro-brasileiros, ${ }^{12}$ parece ser mais provável que foram as frações hegemônicas do movimento de negritude, e não Fanon (revolucionário), com suas críticas ao movimento, que se aproximavam mais das perspectivas buscadas pela ACN:

Na tensa relação de fazer história e fazer sentido, a ACN procurou marcar um lugar importante para o grupo negro paulistano, tentando se por em compasso com o andamento das transformações da sociedade, abrindo uma brecha, às suas custas e às expensas de poucos apoios de alguns intelectuais não negros, para cravar no cenário da modernidade precária emergente de São Paulo uma imagem do negro alternativa à da escravidão, que fosse reivindicativa, crítica, propositiva e combativa. Os condicionamentos sociais para sua produção foram determinantes para reafirmar a marginalidade da iniciativa cultural negra, embora tenha sido capaz de, fato raro, alçar um público não endógeno, num momento favorável, em aberto, com disposições democráticas. (Silva, 2012, p. 270)

Isso sugere que, mesmo que os membros da ACN tenham tido algum contato com as ideias de Fanon, estas ainda não ofereciam, nesse momento, alguma utilidade ao debate afro-brasileiro. Como aponta Silva (2013b) em

\footnotetext{
12 Como mostra o Manifesto da ACN, em 25/03/1960, em repúdio aos "acontecimentos sangrentos de Shaperville" (Silva, 2012, pp. 253-254).
} 
outro lugar, foi preciso que as ideias de Fanon esperassem por uma nova geração de intelectuais e ativistas para serem retomadas e discutidas à luz do contexto brasileiro.

\section{Considerações preliminares}

Mário Augusto Medeiros Silva (2012, 2013a, 2013b) tem oferecido fartas evidências a respeito da importância da Associação Cultural do Negro, em primeiro lugar, para a configuração do movimento negro brasileiro do século XX, na medida em que agregava intelectuais-chave tanto dos períodos anteriores - tais como a Frente Negra Brasileira quanto posteriores à sua emergência e consolidação. Em segundo lugar, a ACN fazia-se importante pela contribuição crucial dessa agremiação para a constituição da sociologia uspiana que compôs o famoso Projeto Unesco, em que se destacam alguns nomes, como Roger Bastide e Florestan Fernandes. $\mathrm{O}$ autor tem argumentado que "esses cientistas 324 sociais se valeram do contato com os ativistas negros, circulando em seus espaços e estabelecendo relações, que foram importantes para seus principais trabalhos sobre a questão racial” (Silva, 2012, p. 230). Dito de outro modo, poderíamos afirmar com o autor que a derrubada do chamado "mito da democracia racial" pelo Projeto Unesco teve o próprio negro - e não a academia, ainda majoritariamente branca - como o seu demiurgo.

Esse dado é relevante para compreender a aposta empreendida pelo autor no que tange às possíveis relações entre Fanon e a ACN. Se o ativismo negro brasileiro foi o grande sujeito dessa virada sociológica, teria sido este também o responsável pela introdução e circulação das ideias de autores negros internacionais no Brasil? Acredito, como procurei demonstrar, que a pergunta, embora preciosa e farta de pistas instigantes, esbarra nas diferenças políticas e teóricas existentes entre Fanon e os intelecuais da ACN, bem como entre as lutas de libertação nacional - em especial as 
de via radical, como a Frente de Libertação Nacional, de Fanon - e as lutas antirracistas no Brasil dessa época.

Ainda assim, esse debate é bastante valioso para a problematização das relações raciais no período pós-guerra e do quanto o Brasil - sempre visto como atrasado - não estava deslocado de importantes debates levantados no âmbito das ciências sociais. A despeito das diferenças aqui levantadas, tanto Frantz Fanon - bem como o conjunto de intelectuais do movimento de negritude - quanto o ativismo negro brasileiro tinham diante de si o desafio de dar conta de três grandes problemas conjugados.

Em primeiro lugar, os efeitos de um processo abolicionista que não apresentou estratégias de inserção do africano e seus descendentes escravizados. Aliás, não apenas a abolição em si, como fenômeno jurídico, mas também todo o metabolismo social se vê marcado por aquilo que Florestan Fernandes (1979) nomeia como "descolonização interrompida”, ou mesmo, em termos fanonianos e nkrumahnianos, o neocolonialismo (Nkrumah, 1967), ou seja, a não superação radical e definitiva do colonialismo levaria as sociedades que conquistaram a independência à saltos históricos que não rompem essencialmente com a sua dinâmica colonial.

O segundo problema, profundamente vinculado ao primeiro, é a permanência da eugenia na sociedade moderna ${ }^{13}$ - como a vertente mais radical, mas não única, do racismo científico - até meados do século XX. Nunca é exagero lembrar que a eugenia não era exclusividade das experiências fascistas, como a alemã, mas uma ciência amplamente difundida nos principais países do centro e da periferia capitalista na primeira metade do século XX. Enquanto Fanon ainda tinha que enfrentar os seus resquícios na psiquiatria e até na psicanálise, autores como Nina Rodrigues, Oliveira Viana e Renato Khel ainda eram vistos e lidos com admiração no

13 Sobre a eugenia, ver o trabalho de Góes (2017). 
período aqui estudado. É verdade, porém, como veremos, que desde a década de 1930 o pensamento conservador de cunho mais biologicista começa a ser relativamente questionado por autores como Silvio Romero e Gilberto Freyre, mas ainda assim persiste, mesmo em argumentos mais sociológicos, a tentativa de responsabilizar o próprio negro pela sua desgraça, isentando, assim, as relações sociais da descolonização interrompida. No caso de Fanon, até alguns importantes expoentes da psicanálise acabam por naturalizar os efeitos do colonialismo. ${ }^{14}$

O terceiro problema está ligado, portanto, ao esgotamento moral (e teórico) do projeto eugenista e, principalmente, ao que se propõe colocar em seu lugar. Se o surgimento da antropologia, da psicologia e mesmo da sociologia foram acompanhados por uma noção de ser humano que vincula mecanicamente natureza, cultura e personalidade, o desvelamento do holocausto gerou uma comoção pública 326 diante das possíveis consequências do conceito de raça: a base epistêmica da eugenia. Assim, vê-se, no âmbito internacional - especialmente na então recém-criada Unesco -, uma busca por experiências antirracistas e, ao mesmo tempo, outros conceitos que permitissem explicar as diferenças culturais sem naturalizá-las.

O problema, já percebido por Fanon nesse momento, é que a troca da raça pela etnia não resolvia, por exemplo, o problema do colonialismo, do racismo e da racialização, mas apenas o colocava em novos termos, sofisticando aquilo que, em essência, permanecia o mesmo. O negro deixava de ser selvagem, mas ainda era visto como primitivo (Silvério, 2013), e a sua cultura não poderia compor as noções de "progresso" e "civilização", nem mesmo nas propostas que consideravam

\footnotetext{
14 Ver, nesse sentido, a crítica de Fanon a Psychologie de la colonisation, de Octave Mannoni (Fanon, 1952, pp. 135-189).
} 
a possibilidade de antropofagia ou cópula com essa cultura. ${ }^{15}$ É nesse sentido que podemos entender a conferência proferida por Fanon em 1956, no I Congresso dos Escritores e Artistas Negros, em Paris. A comunicação, nomeada como "Racismo e cultura", alerta que a substituição do termo raça pelo termo cultura (poderíamos também pensar em "etnia") não resolve o problema do racismo, mas, sobretudo, o maqueia, dando a impressão de avanço quando, na verdade, existe apenas a sofisticação da dominação (Fanon, 1964).

No caso do Brasil, como argumenta Silva (2012), é exatamente este o problema enfrentado pelos negros na década de 1950, especialmente em sua capital econômica - a desproporcionalmente urbanizada São Paulo -, onde o negro é sempre visto como oposto do progresso bandeirante, da modernidade e da superação do atraso. Por essa razão, a ruptura representada pelo ativismo negro, bem como a sua influência junto ao Projeto Unesco, foi muito importante, uma vez que inverte a chave analítica em voga e coloca não sem contradições - o "preconceito racial" no centro do debate, tirando da cultura negra a responsabilidade pela derrubada das barreiras raciais e abrindo espaço para um processo de reconhecimento e valorização desse arcabouço.

A primeira questão, tipicamente fanoniana, como vimos, é que a valorização da cultura negra é apenas uma parte do processo de emancipação e não o seu objetivo único. Ao contrário, o foco na dimensão política da cultura pode levar a uma desconsideração da dimensão cultural da política, invertendo as prioridades da luta social e incorrendo, portanto, na sua inviabilização. A segunda questão, também de matriz fanoniana, é que todas as contradições sociais

\footnotetext{
${ }^{15}$ O caso mais emblemático, para o contexto brasileiro, são os escritos de Gilberto Freyre, que, embora represente uma recusa aberta à perspectiva biologicista de seus antecessores, deslocando, portanto, o debate da biologia para a cultura, ainda via a cultura negra como oposta ao desenvolvimento.
} 
devem ser consideradas em seu tempo e espaço próprios, de forma a evitar anacronismos estéreis e a-históricos.

Isso nos provoca a refletir, quando se equacionam as particularidades das relações raciais no Brasil e na Argélia anticolonial de Fanon, se de fato as suas propostas mais conhecidas na ocasião serviriam para o contexto brasileiro. O Fanon revolucionário terceiro-mundista do I e II Congresso de Escritores e Artistas Negros não parece ser desinteressante para os intelectuais da ACN apenas por uma incompatibilidade de ideias, mas talvez pela própria diferença histórico-concreta pela qual a racialização se deu nos dois contextos em que cada um emergiu.

\section{Deivison Mendes Faustino}

Professor do Departamento de Saúde, Educação e Sociedade da Universidade Federal de São Paulo (Unifesp) e coordenador pedagógico do Instituto Amma Psique e Negritude. 328 Doutor em Sociologia pela Universidade Federal de São Carlos. Mestre em Ciências da Saúde/Epidemiologia pela Faculdade de Medicina do ABC. Graduado em Ciências Sociais pelo Centro Universitário Santo André.

\section{Bibliografia}

BALANDIER, Georges. 1955. Sociologie actuelle de l'Afrique noire. Paris: PUF.

BULHAN, Hussein Abdilahi. 1985. Frantz Fanon and the psychology of oppression. New York: Plenum Press.

CANNELLI, Barbara. 2007. Il secolo "brevissimo" di un'Africa in cerca di identità. Reset Dialogues, 23 jan. 2007. Disponível em:

https://bit.ly/2Pam8Ih. Acesso em: 22 maio 2016.

DIENG, Amadi Aly. 2006. Testemunho do professor Amadi Aly Dieng durante as comemorações do 50ํA Aniversário de Présence Africaine. Salvador:

Organisation Internationale de la Francophonie. (Versão abreviada e traduzida para o português por ocasião da II Conferência dos Intelectuais da África e da Diáspora).

DIOP, Alioune. 2006. A revista Présence Africaine e a Sociedade Africana de Cultura. Salvador: Organisation Internationale de la Francophonie. 
(Versão abreviada e traduzida para o português por ocasião da II Conferência dos Intelectuais da África e da Diáspora).

FANON, Frantz. 1952. Peau noire, masques blancs. Paris: Editions du Seuil.

FANON, Frantz. 1962. L'An V de la révolution algérienne. Paris: François Maspéro.

FANON, Frantz. 1964. Pour la révolution africaine (écrits politiques). Paris: François Maspero.

FANON, Frantz. 1968a. Les damnés de la terre. Paris: François Maspero. (Petite Collection Maspero).

FANON, Frantz. 1968b. Sociologie d'une révolution: L'an V de la révolution algérienne. Paris: François Maspero. (Petite Collection Maspero).

FANON, Frantz. 1969a. Pour la révolution africaine. Paris: François Maspéro.

FANON, Frantz. 1969b. Em defesa da revolução africana. Lisboa: Livraria Sá da Costa.

FANON, Frantz. 1979. Os condenados da terra. Rio de Janeiro: Civilização Brasileira.

FANON, Frantz. 1983. Pele negra, máscaras brancas. Rio de Janeiro: Editora Fator.

FANON, Frantz. 2006. A crítica da negritude. Salvador: Organisation Internationale de la Francophonie. (Versão abreviada e traduzida para o português por ocasião da II Conferência dos Intelectuais da África e da Diáspora).

FANON, Frantz. 2010. Os condenados da terra. Juiz de Fora: UFJF. (Coleção Cultura, v. 2).

FAUSTINO, Deivison Mendes. 2013. A emoção é negra, a razão é helênica? Considerações fanonianas sobre a (des) universalização do "ser" negro. Tecnologia e Sociedade, v. 9, n. 18, pp. 1-16. Disponível em: https://bit.ly/2V6dwGq. Acesso em: 1 ago. 2015.

FAUSTINO, Deivison Mendes. 2015. Por que Fanon? Por que agora?: Frantz Fanon e os fanonismos no Brasil. Tese de Doutorado em Sociologia. São Carlos: UFSCar.

FAUSTINO, Deivison Mendes. 2018. Frantz Fanon: um revolucionário particularmente negro. São Paulo: Ciclo Contínuo.

FERNANDES, Florestan. 1979. Circuito fechado: quatro ensaios sobre o poder institucional. 2. ed. Rio de Janeiro: Hucitec.

FILGUEIRAS, Fernando de Barros. 2012. Guerreiro Ramos, a redução sociológica e o imaginário pós-colonial. Caderno $\mathrm{CRH}$, v. 25, n. 65, pp. 361377. Disponível em: https://bit.ly/38G6YSZ. Acesso em: 26 jan. 2016.

GEISMAR, Peter. 1972. Fanon. Buenos Aires: Granica. (Colección Hombres del Tiempo). 
GILROY, Paul. 1992. The black Atlantic and the politics of authenticity. Santa Cruz: University of California Santa Cruz.

GILROY, Paul. 2000. Between camps: nations, culture and the allure of race. London: Allen Lane.

GÓES, Weber Lopes. 2017. O encarceramento enquanto mecanismo de eugenia contemporânea no Brasil. Comunicação apresentada no III Seminário Internacional de Pesquisa em Prisão, Recife.

GORDON, Lewis R. 1995. Fanon and the crisis of European man: an essay on philosophy and the human sciences. New York: Routledge.

GORDON, Lewis R. 2015. What Fanon said: a philosophical introduction to his life and thought. New York: Fordham University Press.

GORDON, Lewis R.; SHARPLEY-WHITING, T. Denean; WHITE, Renée T. (org.). 1996. Fanon: a critical reader. Cambridge, MA: Blackwell.

GUIMARÃES, Antônio Sergio. 2008. A recepção de Fanon no Brasil e a identidade negra. Novos Estudos Cebrap, n. 81, p. 99-114. Disponível em: https://bit.ly/38N21HU. Acesso em: 20 maio 2015.

HANCHARD, Michel. 2001. Orfeu e poder: movimento negro no Rio e São Paulo. Rio de Janeiro: UERJ.

MACEY, David. 2000. Frantz Fanon: a life. London: Granta Books.

MARZIOLI, Sara. 2013. Ignazio Silone's pan-african detour: Franz Fanon, decolonization, and globalization. Comunicação apresentada no Fanon in Italy: a Symposium - International Journal of Postcolonial Studies, Newcastle.

MOURA, Clóvis. 1983. Brasil: raízes do protesto negro. São Paulo: Global.

MOURA, Clóvis. 2013. Dicionário da escravidão negra no Brasil. São Paulo: Edusp.

NKRUMAH, Kwame. 1967. Neocolonialismo: último estágio do imperialismo.

Rio de Janeiro: Civilização Brasileira.

ORTIZ, Renato. 2012. Cultura brasileira e identidade nacional. 2. ed. São Paulo: Brasiliense.

SARTRE, Jean-Paul. 1943. L'être et le néant. Paris: Gallimard.

SARTRE, Jean-Paul. 1956. Le colonialisme est un système. Les Temps Modernes, n. 123.

SEKYI-OTU, Ato. 1996. Fanon's dialectic of experience. Cambridge, MA: Harvard University Press.

SEREQUEBERHAN, Tsenay. 1994. The hermeneutics of African philosophy: horizon and discourse. New York: Routledge.

SILVA, Mário Augusto Medeiros da. 2012. Fazer história, fazer sentido: Associação Cultural do Negro (1954-1964). Lua Nova, n. 85, pp. $227-$ 273. Disponível em: https://bit.ly/2HDeeTT. Acesso em: 26 jan. 2017. 
SILVA, Mário Augusto Medeiros da. 2013a. A descoberta do insólito: literatura negra e literatura periférica no Brasil (1960-2000). Rio de Janeiro: Aeroplano.

SILVA, Mário Augusto Medeiros da. 2013b. Frantz Fanon e o ativismo político-cultural negro no Brasil: 1960/1980. Estudos Históricos, v. 26, n. 52, pp. 369-390. Disponível em: https://bit.ly/2vVjbEH. Acesso em: 26 jan. 2015.

SILVÉRIO, Valter Roberto. 2013. Síntese da coleção História Geral da África: pré-história ao século XVI. Brasília, DF: Unesco. 


\section{REVISITANDO A RECEPÇÃO DE FRANTZ FANON: O ATIVISMO NEGRO BRASILEIRO E OS DIÁLOGOS TRANSNACIONAIS EM TORNO DA NEGRITUDE}

\section{DEIVISON MENDES FAUSTINO}

Resumo: Neste artigo apresento parte dos resultados obtidos em minha pesquisa de doutorado, intitulada Por que Fanon? Por que agora? Frantz Fanon e os fanonismos no Brasil. Neste estudo, dialogo criticamente com a hipótese de um possível contato ou influência entre Fanon e alguns intelectuais ligados à Associação Cultural do Negro (ACN) no final da década de 1950 e início da década de 1960. Argumento que a factibilidade de um possível encontro presencial entre eles - nos marcos do II Congresso de Artistas e Escritores Negros, em Roma, em 1959 - não seria suficiente para inferir uma afinidade de ideias ou mesmo influência, haja vista as diferentes posições que ocupavam no espectro do movimento de negritude. Por fim, discuto o contexto de circulação das ideias de Fanon e os seus reflexos e particularidades na recepção brasileira.

Palavras-chave: Frantz Fanon; Associativismo Negro Brasileiro; Associação Cultural do Negro.

\section{REVISITING FRANTZ FANON'S RECEPTION: BRAZILIAN BLACK ACTIVISM AND TRANSNATIONAL DIALOGUES AROUND BLACKNESS}

Abstract: In this article I present part of the results obtained in my PhD research entitled "Why Fanon? Why now? Frantz Fanon and fanonisms in Brazil." I analyze critically the hypothesis of a possible contact or influence between Fanon and some intellectuals connected to the Associação Cultural do Negro (ACN) in the late 1950s and early 1960s. I argue that the feasibility of a possible face-to-face meeting between them-in the context of the Second Congress of 
Black Artists and Writers (Rome, 1959)—would not suffice to infer an affinity of ideas or even influence, given the different positions they occupied in the spectrum of the black movement. Lastly, I discuss the context in which the ideas of his poem thrived and their effect and particularities on Brazilian reception.

Keywords: Frantz Fanon; Black Brazilian Activism; Associação Cultural do Negro.

Recebido: $17 / 01 / 2017$

Aprovado: 26/11/2018 